Nunt. Antiquus, Belo Horizonte, v. 15, n. 1, p. 131-154, 2019

\title{
Euterpe, atenção e deleite
}

\section{Euterpe, Attention and Delight}

Sérgio Alcides

Universidade Federal de Minas Gerais (UFMG), Belo Horizonte, Minas Gerais / Brasil sergioalcides@uol.com.br

Resumo: Entre as nove filhas de Zeus e Mnemósina, Euterpe era conhecida como a Aprazível, que espalha alegria, e tinha como principal atributo iconográfico o aulo, um instrumento de sopro. Na Antiguidade tardia, ela foi apontada como a Musa ora da música, ora da poesia lírica. Originalmente, porém, as irmãs não tinham alçadas específicas: elas se incumbiam conjuntamente de inspirar os artistas, assim como a fruição das artes. Essa tarefa se ligava à paidéia grega, ideia de "educação" na qual o aprendizado não exclui o prazer. A consideração das condições presentes do contato com objetos artísticos, em face da onipresente indústria do entretenimento, suscita a discussão do papel das Musas - e de Euterpe em particular - na preservação da faculdade humana da atenção, indispensável à experiência estética.

Palavras-chave: Euterpe; Musas; inspiração; atenção; experiência estética.

Abstract: Among the nine daughters of Zeus and Mnemosyne, Euterpe was known as the Delightful one, the one who brings joy, and had as her main iconographic attribute the aulos, a wind instrument. During late Antiquity she was declared the Muse either of music or of lyric poetry. Nevertheless, originally there were not specific domains for each of the sisters: they were supposed to jointly inspire the artists, as well as the enjoyment of the arts. Their task was related to the Greek paideia, an idea of "education" in which learning does not exclude pleasure. Considering the present conditions for the contact with artistic objects, given the widespread entertainment industry, a discussion is elicited about the role of the Muses - and Euterpe's in particular - in the preservation of the human faculty of attention, indispensable to aesthetic experience.

Keywords: Euterpe; Muses; inspiration; attention; aesthetic experience. 
A aparição da Musa ofusca: muitos flashes disparam em volta dela, uma descarga de perguntas gritadas, gente que se acotovela em busca do melhor ângulo de visão. Ela mal compreende tantos apelos, enquanto se dirige, olímpica, até o púlpito. Os flashes aumentam, os gritos também. Ela está posando, talvez queira proferir algumas palavras. Sorri, experiente, complacente. Põe as mãos para trás, a fim de mostrar melhor o traje. É um conjunto chamativo, justo no corpo, azul-escuro com estampas coloridas. O paletó cobre uma blusa, também preta, mas rendada, por onde transparece o mármore da pele. Tigres agarram as pernas das calças e as abas e as mangas do paletó, bordados com linha dourada, em competição com a tintura da cabeleira musaica: línguas muito vermelhas para fora, dentes afiados e gulosos reluzindo. Também é amarelo o laço bufante que se derrama sobre o ansiado colo, onde se nota um discreto pingente de ouro. Flores vermelhas na lapela, chamativas, entre outros motivos em azul-marinho, preto e verde.

Não mais solene do que o necessário, a cantora se vira para mostrar as costas do paletó. Outra bateria de flashes atiça um tigre a mais. Acima dele, uma grande âncora branca e vermelha, com quiasmas em azul-claro: a imagem de uma firmeza estável no meio de tanto rebuliço, feita de um bom conhecimento das profundezas. E, atravessando tudo, de ombro a ombro, para quem soubesse algum grego, a ampla inscrição

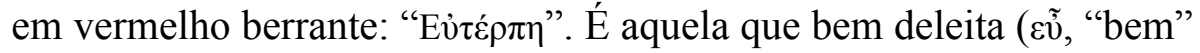
$+\tau \varepsilon ́ p \pi \varepsilon v$, "agradar"). Ou seja: Euterpe, a Aprazível.

Em posição estudada, mas não exatamente hierática, ela joga o peso do corpo sobre uma das pernas, com as mãos na cintura, saltos altos, mas não demais, com que pisa o tapete extravagante, roxo. Enquanto olhares e lentes se deliciam atrás dela, volta-se para a parede contraposta: um tabique branco, onde sobressaem os nomes de potentes patrocinadores: além de Pandora (a joalheria), a Mercedes-Benz, a American Airlines, a American Express e outras marcas. E o nome do grande acontecimento: "Billboard Women in Music" (cf. MADONNA..., 2016 (ד).

Entre a chusma de repórteres, está a jovem Katherine Cusumano, da revista $W$, pertencente ao grupo americano Condé Nast. Bem aparelhada, ela busca uma conexão para consultar o oráculo. "Euterpe 
era a Musa da música na mitologia grega antiga", escreve, depois de "googlar". Na edição de 11 de dezembro de 2016, a jornalista especializada em moda informa: "Madonna, Rainha do Pop e Mulher do Ano, está entre as Musas". E acrescenta: "Graças a Alessandro Michele" (CUSUMANO, 2016).

Trata-se de um estilista da grife italiana Gucci, que desenhou o conjunto usado por Madonna no grande dia. Ela estava prestes a receber o prêmio máximo da celebração das Mulheres na Música, oferecido anualmente pela revista musical de Hollywood, em Nova York. "Obrigada, Gucci, pelo traje lindo!" - escreveu a cantora, ao publicar uma foto no Instagram. Era o lugar para esclarecer a inscrição indecifrável. "Em grego, quer dizer: a Deusa da Música, que traz ALEGRIA!"

Os fãs responderam nos comentários: "U R THE GODDESS AND IT'S UNIVERSALLY TRUE”, afirmou @george_loves_life, em letras garrafais, acrescidas de vários emoticons carinhosos (cf. [SEM título], 2016 ك). “Sei bellissima”, elogiou@crestastefaniasc, com razão. "Più passano gli anni e più diventi bella". E @ rickyandreas exclamou: "You are the light our hope". Este estava inspirado; comeu a vírgula e acabou dizendo mais: ela é a luz-esperança que tanto importa para uma coletividade (que ele evoca usando o pronome our, e pela qual - como os vates antigos - ele fala).

Possa a Musa ainda trazer alegria e incitar aos mortais a elevação que o nome de "humanos" só pode almejar graças a uma inspiração dela mesma - dela e de suas irmãs, que formam o coro das nove filhas de Zeus e Mnemósina. Tarefa complicada, entre cliques e claques, flashes e hashtags, que visam à Musa ao mesmo tempo que desviam dela a atenção de seus servidores. O clarão dos refletores ameaça a luminescência que ela própria emite desde tempos imemoriais.

O showbizz é um contexto difícil para a Musa. São muitos apelos simultâneos, o tempo todo, e raramente suaves. A invocação se tornou uma indústria. Seu serviço é requerido já, com máxima urgência, em toda a parte, em todos os instantes, para todos os fins. Só mesmo uma equipe dá conta de tantas encomendas, tanta solicitação aflita e inadiável. Para ter acesso à Musa, é necessário invocar primeiro sua assessoria de 
imprensa, marcar hora para o frenesi. Era mais fácil ser só deusa do que ser também celebridade.

Boa filha de sua mãe, ela fora criada para relembrar a verdade, cujo conhecimento detém, como inquilina do Olimpo e conviva dos deuses. Mesmo Euterpe, a Deleitosa, dançava conforme a mousiké, ou seja: tudo o que estava na alçada mental e emocional das Musas, todos os muitos dons que somente elas podiam conferir aos humanos. Alegrar não precisa ser falaz. Porque a ninguém tinha ocorrido a ideia de alguma contradição entre a verdade e o deleite, ou de que o prazer pudesse ser falso, não sendo vicioso. Euterpe e suas irmãs ensinaram a ficção a Hesíodo: "Sabemos dizer fingimentos que se assemelham a verdades" (Teogonia, vv. 27-28). E desse modo o verdadeiro se desprendeu da mera factualidade.

Mas trata exatamente desta a maioria das solicitações que hoje atormentam a Musa. Que pensa ela sobre o lançamento do satélite? Aprova a volta dos chapéus? Pretende assistir às Olimpíadas? Gostou da entrega dos Oscars? Alguma palavra sobre a eleição de "Bozo"? Lamenta ou não o divórcio do galã? Enquanto seu álbum sobe nas "paradas", exige-se da Musa a revelação de suas opiniões em geral: ela caiu refém da doxa. Às vezes, tem vontade de dizer apenas: Leave me alone! - como fazia certa colega sua, tempos atrás.

Além disso, a cantora sente falta da companhia das Graças (como ela, muito aprazíveis), que no coro junto com as filhas da Memória representavam a lindeza, a delícia e a abundância gratuitas do mundo natural. $\mathrm{O}$ negócio da Musa não tem mais gratuidade; meia entrada para estudantes, se tanto. $\mathrm{O}$ acesso não sai barato: o download custa um preço. O cachê da Musa é alto: não é disso que ela se queixa. O problema é a redução de seus talentos a valores. Nem o hálito divino é hoje tão excepcional que não se possa reproduzir em milhares de frascos a serem vendidos online ou não, na terra, por manequins, e no céu, por aeromoças, duty free. Por trás do canto delicioso, ouve-se o ritmo atordoante das asas pretas: uma esquadrilha de trezentas harpias vem recolher os lucros - as arrebatadoras, as abastecedoras contábeis do Inferno.

A cantora ainda se lembra do instante em que inspirou a certo vate malogrado uns versos que já têm mais de dois mil anos, mas até hoje estalam como pão fresco: 
De duro ferro é a última das raças,

E, nessa idade do filão mais baixo,

Tudo irrompeu de pior e mais sacrílego;

Pudor, verdade e fé se despediram,

E em seu lugar vieram instalar-se

A fraude e o dolo, a injúria e a violência,

E o celerado amor à propriedade.

(OVÍDIO, Metamorfoses, I, vv. 127-131).

Era a Idade do Ferro. Cismando, a deusa se pergunta o que teria escrito o poeta se tivesse chegado a conhecer a Idade do Níquel...

No fundo, ela não sabe mais a quem serve nem por quem é servida. A ordem antiga era bem cômoda quanto a isso. As Musas foram criadas para o deleite dos deuses, que valorizavam a harmonia das danças e das vozes concertadas, e apreciavam o canto das façanhas humanas. Os mortais, cultuando-as, poderiam através dos seus favores alcançar uma nesga de glória, tornando-se - ainda que momentaneamente - também criadores.

Mas a cosmologia não resistiu à ascensão dos cosméticos. As notas musicais passam pelos ouvidos humanos como o blush pelas bochechas. Euterpe não se manifestou sobre a tradução de seu nome por "Alegria", numa edição brasileira da Teogonia (HESÍODO, 2007, p. 107); mas certamente não foi ela quem inspirou a opção tomada em inglês por Martin West, que a chamou de "Entertaining" (HESÍODO, 1988, p. 64). É verdade que térpein, significando "agradar", "alegrar", "aprazer", "deleitar", "deliciar", admite a tradução por "entreter". Ocorre que esse verbo, na nossa cultura, atrai o contágio de noções dificilmente compatíveis com os afazeres da Musa, sobretudo a ideia de preenchimento casual do tempo livre, na folga, ou a anestesia da consciência, durante o trabalho manual ou repetitivo: a fruição do simbólico vivida como atividade inespecífica, inessencial, incolor e inócua.

Na Grécia antiga, Euterpe e suas irmãs eram padroeiras da paidéia - ou, mal traduzindo, da educação (MURRAY, 2004, p. 379 et seq.). Sua ação se dava conforme a virtude indicada no nome de cada uma: a que afama (Clio), a que apraz (Euterpe), a que reverdece (Talia), a melodiosa (Melpomene), a que apraz dançando (Terpsícore), a adorável (Érato), a de tantos hinos (Polímnia), a celestial (Urânia) e a de bela 
voz (Calíope). Conjuntamente, elas exerciam uma influência decisiva e definitiva na vida de todos os cidadãos instruídos. Isso pressupunha uma relação nada superficial com a mousiké, e principalmente nunca isenta de consequências (VERNANT, 2007, p. 363 et seq.). O vínculo estabelecido era de compromisso existencial. AAprazível não se desviava dessa tarefa, porque nem era concebível o "entretenimento" que de algum modo não constituísse aprendizado.

Neste sentido, mais termos em grego se apresentam à jaqueta da Musa. Um dicionário etimológico registra a ocorrência, em obras de Eurípides e Platão, do substantivo amousía, significando "falta de instrução", relacionado ao adjetivo iônico e ático ámousos - literalmente, "sem Musas" - para designar a pessoa que não recebeu educação (BEEKES; BEEK, 2010, "Moṽ $\alpha$, f.”). Em outros autores, dá-se o verbo mousóomai, "ser conduzido e educado pelas Musas" (BEEKES; BEEK, 2010). Embora não exista acordo sobre a etimologia da palavra grega mousa, esses vocábulos contribuem para reforçar o nexo entre as Musas e a raiz indo-europeia *men-, da alçada do pensar e da atividade intelectual (SEMENZATO, 2017, p. 7). Descendem daí, por exemplo, o verbo grego mantháno ("aprendo"), o latino memorare ("recordar", "contar") e o italiano dimenticare ("esquecer"), assim como o substantivo alemão Meinung ("opinião", "ideia"), o inglês meaning ("sentido") e o português mente (assim como a mentira). Revendo as muitas tentativas de decifração etimológica da palavra (algumas bem fantasistas), Semenzato recolheu em conjunto "as noções de desejo, aspiração, mistério, memória, união, atração, ataque e água" (SEMENZATO, 2017, p. 9). Mas ela também poderia listar a de "atenção": "ação de fixar o espírito em algo" (HOUAISS; VILLAR, 2001, “atenção, s. f.”). É como já foi definida a raiz indo-europeia da Musa: "fixar o espírito sobre uma ideia, uma arte" (BRANDÃO, 1986, v. I, p. 202).

A fixação do espírito sobre o que quer que seja deve ser o problema contemporâneo mais crucial. Isto, se não for a própria subsistência de qualquer foro mental e emocional denominável de "espírito", dilacerado como Orfeu numa rede infinita de elos e hiperligações, ou assediado como Penélope por incessantes mensagens publicitárias. Toda uma indústria planetária do entretenimento está vendendo diversão: "digressão", "desvio", “desatenção". Só Euterpe e suas irmãs podem subtrair uma 
pessoa da imensa massa de amusados. Inspiradoras dos artistas, elas também ensinam a fruir a arte e o mundo, estendendo a corda do arco certeiro da atenção humana.

Euterpe, entre todas, se encarrega de conjugar o esforço e a delícia. Depois de tanto tempo, a Musa ainda não compreende direito como foi que um dia separaram o prazer e o cultivo, ou como foi que a edificação passou a ser razão de tédio.

Aliás, depois que a inspiração virou trabalho e o canto, produção, a própria deusa conheceu o aborrecimento. Que faz ela depois do expediente? Assiste à televisão? Joga no computador? Entra no Facebook para postar selfies com Dante ou Anna Akhmátova?

Diz um erudito que só o "sopro do espírito" pode afugentar as harpias (BRANDÃO, 1986, v. I, p. 237). Em sentido figurado, as nove irmãs eram as divindades mais propícias a esse fim, como inspiradoras das artes. Euterpe, contudo, também o era em sentido literal. Uma tradição atribui a ela a invenção do aulo (aulós). Em grego, o termo designava diferentes instrumentos de sopro, como certos tipos de flauta, ou outros mais parecidos com o oboé moderno.

A flauta dupla em particular se tornou o principal tema da iconografia da Musa. Ainda que outras fontes creditem a invenção a Atená. Diz o mito que a deusa cívica fez o instrumento (em latim chamado tibia) com ossos de um cervo, no que terá inventado também a auletiké - a arte de tocar os sopros (WILSON, 1999, p. 60 et seq.). Entretanto, a filha favorita de Zeus não gostou nada de ver sua imagem refletida, ao assoprar seu invento: o rosto desfigurado pelas bochechas infladas the parecera um horror. Desgostosa, atirou longe a flauta indecorosa. O sátiro Mársias, então, livre de maiores escrúpulos com o decoro, tomou-a para si e aprendeu a tocá-la, descobrindo o deleite físico e com frequência sensual dos sons que podia espalhar pelos ares.

$\mathrm{O}$ rosto inflado da deusa guerreira aparece com muita graça num vaso datado de meados do século IV a. C., pertencente à Coleção Colombo, do Museu Arqueológico Nacional, de Florença (MANF, 2013). Ela deixa o escudo e a lança de lado, para experimentar a melodia, sentada diante de uma pequena oliveira (Figura 1). 
FIGURA 1 - Atená tocando o aulo. Cratera, cerâmica de figuras vermelhas. Itália, 375-350 a. C. Coleção Colombo, Museu Arqueológico Nacional, Florença.

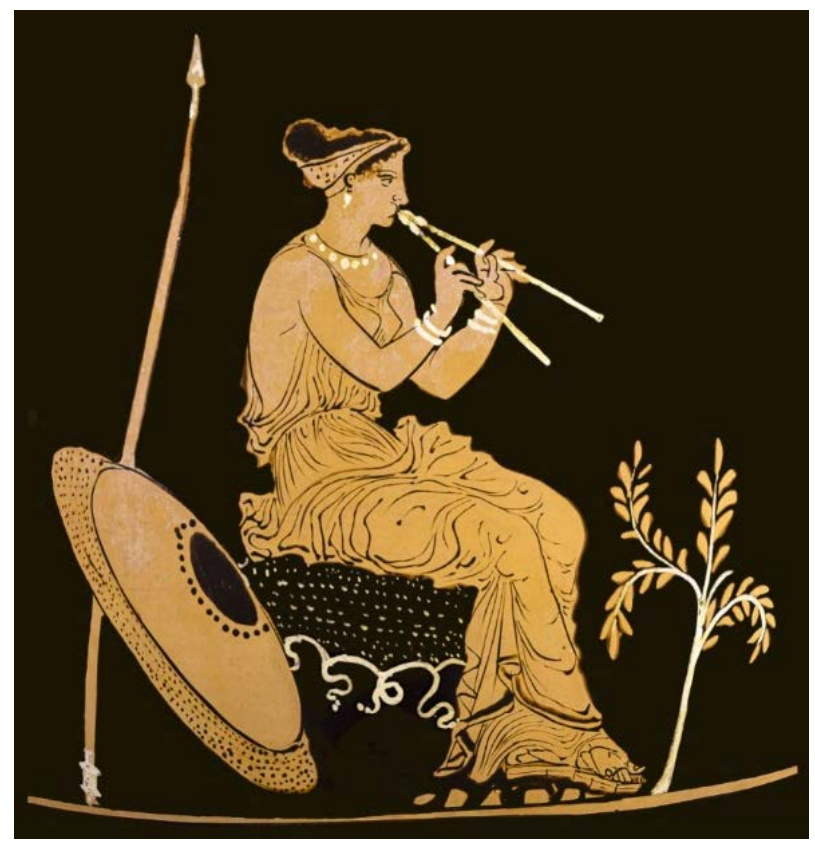

Fonte: CRATERE..., 2013.

A mesma pose, com outros atributos iconográficos, é frequente na representação de Euterpe, seja quem for a verdadeira inventora. Um exemplo mais antigo se vê numa píxide de cerâmica do Museu de Belas Artes de Boston, de procedência ática, datada de 460-450 a. C. (MFA). A Aprazível está aqui em círculo, a fundo branco, junto de cinco irmãs, em volta da peça que não tem mais do que 15 centímetros de diâmetro (Figura 2). Outros instrumentos se harmonizam no concerto, como a fórminx (uma cítara em forma de crescente), a sírinx (que é a flauta de Pã) e a lira. Esta se vê na mão esquerda de um pastor-poeta que, segundo informa o museu, não é Hesíodo (como se pensava) e sim Arquíloco. 
FIGURA 2 - Euterpe, do "Pintor Hesiódico". Píxide, cerâmica de fundo branco.

Grécia, Atenas, 460-450 a. C. Museu de Belas Artes, Boston.

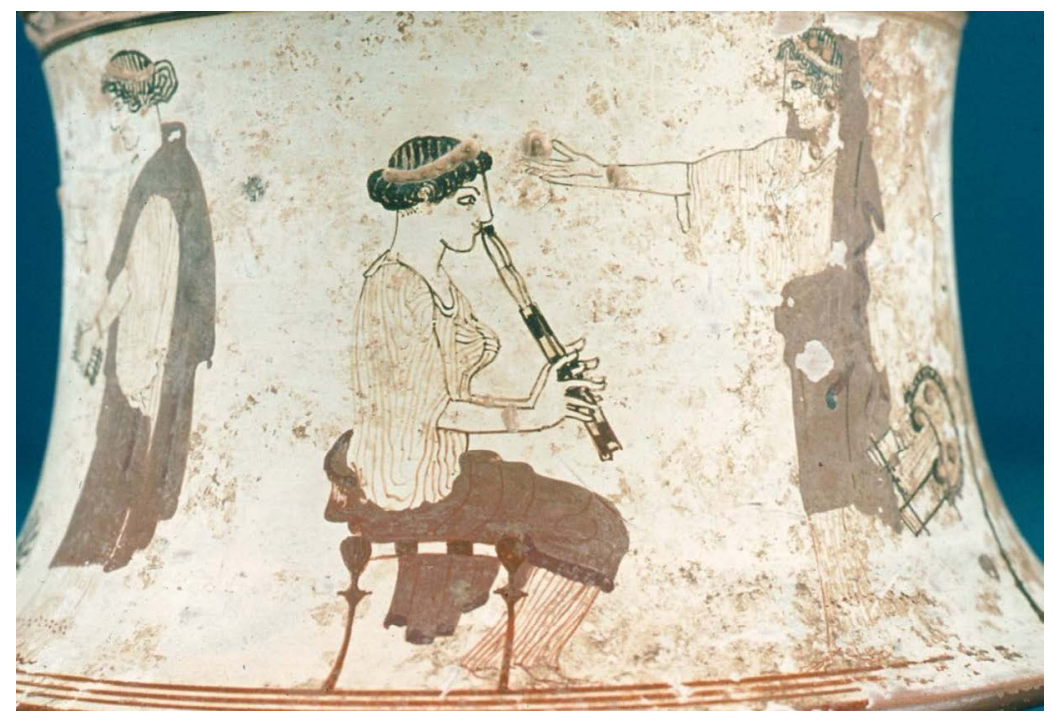

Fonte: PYXIS..., c2019.

"Píxide" é hoje uma palavra preciosa (rara como a coisa que designa). Para as mulheres gregas da Antiguidade foi um termo corriqueiro (pyxís), ligado a um objeto do cotidiano. Em geral era um vaso cilíndrico, que tinha tampa e servia para guardar joias ou cosméticos. Ninguém precisa ser Madonna para ter no quarto uma caixinha parecida com essa, na qual se depositam fragmentos da identidade de uma mulher, que junto do seu corpo contribuem para formar a imagem da pessoa, singular e intransferível, e na ausência dela se transformam em metonímias imperfeitas, memórias. Esse item da intimidade, como testemunha o exemplar de Boston, poderia oferecer uma oportunidade a mais para contemplar o laço estreito entre as Musas e a criatividade humana. Mais que isso, a presença reiterada dessa relação no dia a dia.

A Musa que hoje atrairá milhares de seguidores no Instagram também fez sucesso na rede social dos vasos gregos antigos. Neles, o tesouro maior está por fora, com as narrativas mitológicas que envolviam o valor de uso dos recipientes. Assim como na píxide de Boston, cada um revela um aspecto da inseparabilidade entre a religião, as artes e a 
vida prática na cultura grega, em todos os cômodos da casa, do quarto à cozinha, assim como na viagem final ao Hades, em urnas funerárias.

Outra imagem de Euterpe com a flauta dupla está num vaso da Coleção Lamberg, hoje no Museu de História da Arte, de Viena. Ela aparece aí em duo com Terpsícore, que dedilha uma cítara do tipo dito testudo, cujos braços são feitos de chifres (LA BORDE, 1813, p. 11-12, prancha XI). Diante das duas irmãs, acha-se Apolo, marcado pela coroa de louros, de pé, hierático, em atitude de profunda concentração (Figura 3). O que sobressai, aí, além do vínculo com o deus também chamado Mousaguétes (o "líder" das Musas), é a ênfase que o artista pôs na audição musical, com o vulto estático do deus apoiado em seu báculo, pressupondo-se todo um movimento interior provocado pela symphonía: a consonância musaica.

FIGURA 3 - Apolo ouve o concerto de Terpsícore e Euterpe. Cratera de sino, cerâmica de figuras vermelhas. Itália, Apúlia. Coleção Lamberg,

Museu de História da Arte, Viena.

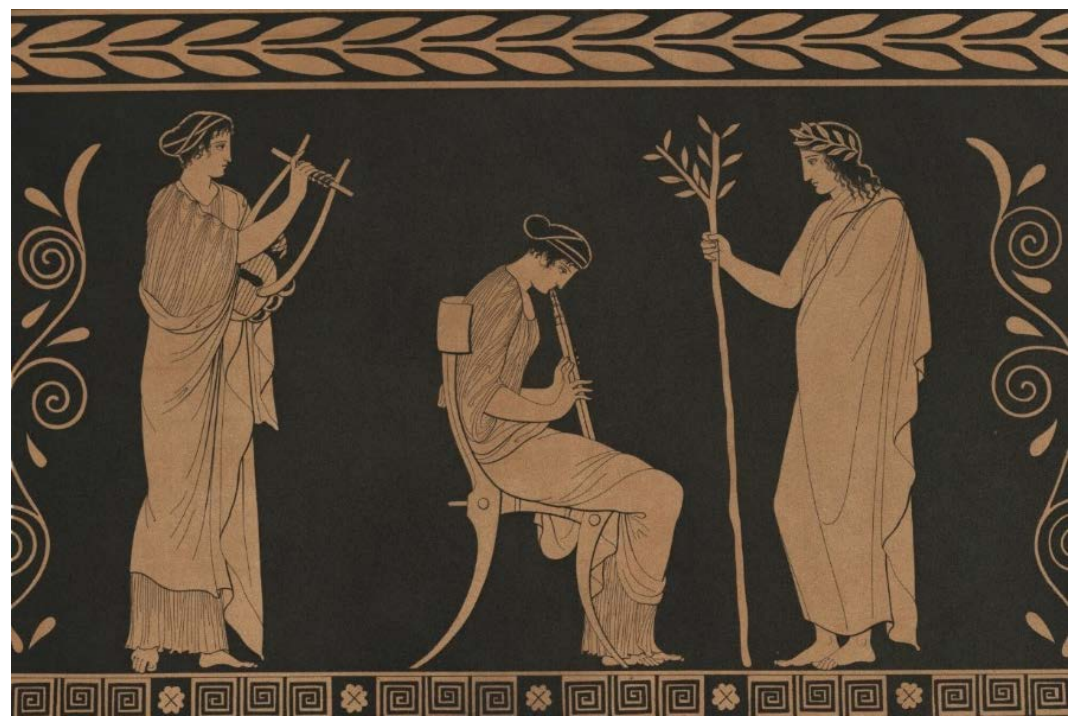

Fonte: La Borde, 1813, prancha XI

A pintura é feita com a técnica de "figuras vermelhas", indicando datação posterior aos finais do século VI a.C. Outro vaso da mesma época elabora uma imagem de fruição musical bem diferente, na qual a 
presença e o movimento dos corpos integram com a maior intensidade toda a experiência dos participantes (LA BORDE, 1813, p. 47-48, prancha XXXII). A cena é de uma bacanal (Figura 4). Euterpe encarna aí numa mênade que segue um cortejo de foliões, assoprando o aulo e trajando e uma túnica transparente representada com grande habilidade, além de um engraçado barrete frígio. Os quatro foliões ostentam insígnias da iconografia associada às festividades de Baco: a tocha, os ramos de árvores, as bandeirolas, a flauta dupla que segundo algumas fontes era o instrumento preferido do deus do vinho (LA BORDE, 1813, p. 4748, prancha XXXII). Os rapazes acompanham a musicista dançando animadamente: o que a antecede e o que vem depois dela olham para trás, chamando o último, enquanto avançam; à frente de todos, o primeiro se contorce, curvando as costas com languidez, braços erguidos adiante, joelhos dobrados em passos de forte expressividade, que, pelo gestual evocado, quase fazem o jarro cantar sozinho um ditirambo. Este principalmente, mas as outras quatro figuras também, denotam a máxima concentração na cena que vivem, em estado de aparente ebriedade.

FIGURA 4 - Bacanal. Cratera, cerâmica de figuras vermelhas. Grécia. Coleção Lamberg. Museu de História da Arte, Viena.

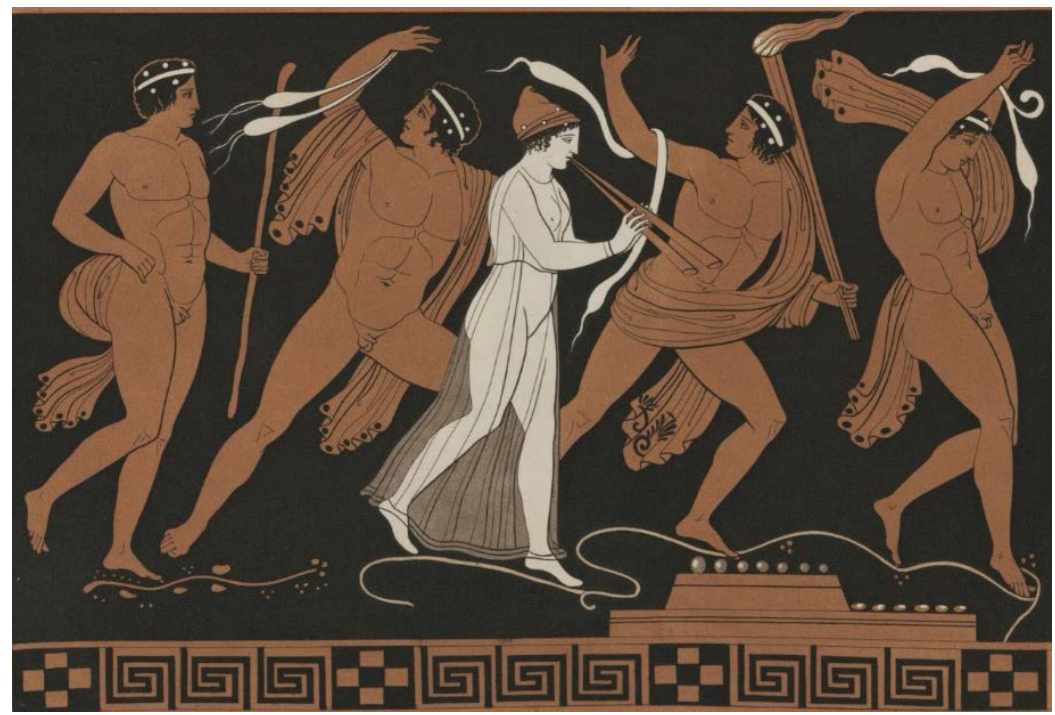

Fonte: La Borde, 1813, prancha XXXII. 
No primeiro caso, os corpos estão presentes apenas para indicar uma "ausência" ou um alheamento de tudo o que não fosse a música: e é esta a forma do compromisso existencial figurada. No segundo, a forte presença corporal e o dinamismo da dança manifestam outra variação da intensidade com que a ação das Musas enlaça os mortais e a experiência das artes. São dois modos, contrastantes, mas de maneira nenhuma opostos ou excludentes, de plena imersão estética. Ambos, mesmo diversos, opõem-se igualmente à noção de "entretenimento" hoje associada ao contato com objetos artísticos, do reino simbólico. E manifestam, com maior ou menor envolvimento corporal, a atenção esperta que as Musas almejam incitar.

A Aprazível não se conforma com o desperdício de seus eflúvios num mero passatempo mercantil, descomprometido, que esteriliza a fecundidade das artes. Não se trata de comparar, como faria o elitista, "Like a Virgin" com uma canção qualquer de Schubert. Uma sonata de Mozart soando no elevador ou uma sinfonia de Vivaldi numa "praça de alimentação" encerram o mesmo valor estético de qualquer outra forma de poluição sonora. Já o "metaleiro" aficionado tem em comum com o melômano mais exigente o envolvimento profundo que ambos dedicam à música: para um e para o outro, o que entra pelos ouvidos se calca para sempre na pessoa, adensando a vida interior do indivíduo. Independentemente da qualidade dos resultados artísticos, o esforço musaico não se completa sem uma qualidade específica da fruição, da experiência. Sem ela, a paidéia vira um chiclete.

$\mathrm{Na}$ fruição mora o perigo. O tédio contemporâneo da Musa, diante dos flashes e dos paparazzi, tem a ver com uma longa memória de repressões. Os potenciais disruptivos do prazer estético nunca foram ignorados pelos poderes estabelecidos. Nos tempos clássicos de Atenas, a delícia melodiosa do aulo chegou a ser proibida; num contexto fortemente centrado na palavra do orador, cresceu a desconfiança frente a um instrumento que calava a boca do musicista, aliciando a audiência de maneira às vezes extática (WILSON, 1999, p. 87). Platão expressou reservas à entrada dos auletas na cidade ideal: "Não fazemos nada de extraordinário", diz Sócrates, "se preferimos Apolo a Mársias, e os instrumentos de um aos do outro" (PLATÃO, República, 399e). 
A passagem alude à desmedida do sátiro auleta, que lançou ao deus da lira um desafio musical. O prêmio de quem vencesse seria poder fazer o que quisesse com o perdedor, que obviamente não foi o senhor de Delfos. Para Mársias, a consequência foi ser esfolado vivo.

As palavras de Sócrates sobre o caso documentam a crescente "polarização - chegando por vezes à hostilidade - entre a lira e o aulo" (WILSON, 2000, p. 69). Já vimos, porém, que essa dissonância não existe do ponto de vista infenso à normatividade do pintor do vaso duplamente deleitável de Euterpe e Terpsícore (Figura 3). É a perspectiva mais afim à das filhas de Mnemósina. No que concerne especificamente à Aprazível, que foi apontada como a Musa da música e, em algumas fontes, da poesia lírica, a canção exprime o modo mais pleno da consonância entre as cordas (que liberam a voz para o canto) e o sopro (que inebria, mas harpias espanta).

A atribuição de especialidades às nove irmãs se deu tardiamente, e em detrimento da tradição arcaica de concebê-las como um coro de executantes e inspiradoras das várias artes, sobretudo a poesia, o canto e a dança. Originalmente, a ênfase era posta na ação conjunta das irmãs (MURRAY, 2004, p. 367). Um comentador moderno observa como os autores helenísticos se contradizem uns aos outros a respeito da alçada de cada Musa - discussão que para ele não passava de uma "tolice de pedantes", a qual podia ser refutada com "um conhecimento bem reduzido da literatura clássica" (ROSE, 1990, p. 144).

Divindade auletrida, facilitadora do "sopro do espírito", a Musa da música terá inspirado nos tempos modernos um enorme repertório, que vai desde os solos e os duos até os concertos sinfônicos liderados pela flauta, o clarinete, o oboé, o trompete ou até o saxofone e a trompa. Um exemplo brasileiro, entre mil, poderia ser a ária-choro das "Bachianas Brasileiras no 6", de Villa-Lobos, composta em 1938 para flauta e fagote. Duas virtudes justificam a lembrança: primeiro, o aspecto lírico da obra, que atira o ouvinte de imediato na vida interior que a Musa pretende nutrir; segundo, a forma dialogal adotada, através de uma exploração audaciosa da técnica do contraponto, que vem aqui ressaltar a complexidade da experiência do próprio "eu", que tem mais de um timbre lá dentro, e nunca menos que duas melodias entrelaçadas. 
Uma terceira razão poderia ser a confessada admiração do compositor pela música de Pixinguinha, à qual Villa-Lobos dedicou tanto estudo quanto a qualquer manual de harmonia clássica (MALTA et al., 2016). A autoridade do autor de "Carinhoso" sobre o dos "Choros" reforça o interesse modernista pelas fontes populares como um meio de renovação da arte erudita. Não é crível que o coro de Apolo endosse a falácia de uma indistinção entre o popular e o erudito, dada a natureza diversa dessas tradições (por mais que se interseccionem) e dos seus meios de reprodução e circulação. Mas nada indica que as Musas favoreçam o equívoco inverso dos que propõem uma hierarquia entre os dois gêneros, cedendo a palma ao erudito (às vezes denominado, com ridículo esnobismo, de "música séria").

— "Aff!" - diria Euterpe, num suspiro, talvez lixando as unhas, diante de uma questão que não poderia parecer-lhe mais fútil. Um de seus alunos mais aplicados é justamente o grande Alfredo da Rocha Viana Filho, o Pixinguinha, cujo primeiro instrumento foi a flauta. Também ele sabia apontar o caminho para a vida interior através de sugestões melódicas assopradas com habilidade. Muitas obras suas exploram a consonância entre as cordas e o sopro, ignorando a rivalidade ática mencionada acima. Uma peça que pode ter sido inspiradora para VillaLobos é o "choro melódico" "Sofres porque queres", que Pixinguinha compôs com outro flautista importante, Benedito Lacerda, e que em 1917 foi apresentado como "tango" em gravação da Casa Edison do Rio de Janeiro (Odeon, 121.364; VASCONCELOS, 1964, v. 1, p. 87). A nota melancólica mais enfatizada na ária-choro surge aqui acompanhada pelo violão sincopado, que tem sete cordas como a lira de Terpsícore. Bem-humorada, a Musa também terá inspirado, nesse caso, o impagável título da composição.

Certamente o inspirou, pensando bem: o choro todo transpira essa qualidade conversacional característica dos gêneros líricos, tão frequentemente voltados para a imitação do diálogo interior, em que o "eu" descobre uma segunda pessoa ora na própria consciência, ora na figuração de alguém que partiu ou - arquetipicamente - na Musa. Aí se embasa Northrop Frye para definir a lírica como "elocução ouvida a 
furto" (1973, p. 245). Mas é interessante frisar melhor que o decisivo nesse modo de a definir é a fruição - coisa que o teórico canadense não enfatiza tanto, ao tomar essa ideia de empréstimo às "Reflexões sobre a poesia", de John Stuart Mill.

A oitiva então põe num mesmo plano os dois campos que as fontes helenísticas atribuíam a Euterpe: a música e a poesia lírica. Esta, com frequência, alude ao vínculo imemorial entre a palavra e a melodia, mesmo quando voltada para a leitura silenciosa, que soa apenas na consciência do leitor, que - quando muito - move os lábios diante do texto, sem emissão exterior. "Sonzinho" foi o nome dado a uma das formas mais fecundas e longevas da poesia lírica, o sonetto, criado por juristas e "notários" da corte siciliana de Frederico II, na primeira metade do século XIII. Para não mencionar a canção, forma também silente que se destaca em obras de mestres como Dante, Petrarca, Garcilaso de la Vega, Camões e ene outros, em várias línguas.

A poesia moderna herdou essa ambivalência entre o som e o silêncio, que o lirismo tende a realizar como conversa oferecida furtivamente a uma audiência. A cantora pode então ser objeto não tanto de uma invocação (já vimos como ela anda assoberbada de solicitações do tipo), mas de uma interlocução. É assim que ela assume a posição mística do "amado" no primeiro poema de Citas y comentarios, de Juan Gelman (1994 p. 1), no qual o poeta veste a persona de Santa Teresa d'Ávila:

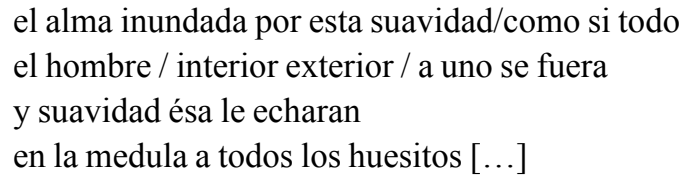

(GELMAN, 1994, p. 1.)

O "amado" exerce o influxo musaico sobre a santa, o qual resulta no poema. $\mathrm{O}$ tom de súplica envolve a narrativa do episódio, em que a vida interior se reconcilia com o "todo" do indivíduo. A presença da Musa inunda o poeta de uma suavidade fluente: ele é sua flauta de "ossinhos"; ela preenche os "tutanos" dele: 


\section{[...] esta vida}

que me vivís / los tuétanos que vosme

conversás en silencio como patria

o gran olor suavísimo

que no se sabe dónde está / ebriedad

que nada intenta / ni querer / ni pedir

sino que me besés con besos de tu boca [...]

(GELMAN, 1994, p. 1.)

A Musa está vivendo a vida ao poeta, numa transitividade indireta. Ela lhe está conversando sua intimidade. Nessa interlocução imaginária, o silêncio da Musa é a pátria do poeta. A falta de uma resposta objetiva não deixa de propiciar a ele a ebriedade erótica que motiva o poema.

Porém vem mais para o final o trecho mais crucial para a consideração dos feitos de Euterpe: porque sin vos / ¿qué soy sino desastres? / ¿a dónde /voy a parar desviado de vos? [...] (GELMAN, 1994, p. 1).

Sem a Musa, o poeta se extravia, à mercê da má estrela. Os "desastres" são também a perda do estro, do furor criativo, que para ele significa a impossibilidade de ser quem se é: a perda de si mesmo.

Nas interrogações finais do poema de Gelman, subjaz a problemática fundamental da criação artística, que atravessa os séculos e todas as teorias, inesgotável, e para a qual o mito das Musas pretendia oferecer uma resposta - a qual manifesta, ela própria, um testemunho da criatividade humana. No fundo, trata-se "daquele lugar misterioso, situado fora ou dentro do poeta, do qual emana a inspiração artística" (LEVY, 2012, p. 902).

A questão se torna dramática nos tempos modernos, quando a resposta mítica passa a ser, em si mesma, inaceitável. O primado das ciências e de uma razão pragmática, que se ergueu lentamente a partir do século XVII, impõe uma barreira teórica: o que for misterioso fica fora de cogitação. Nem por isso o problema deixou de interessar aos artistas que também se dedicaram a refletir sobre seu ofício.

Para Benjamin Britten, membro da corte de Euterpe como Musa da música, a criação artística contrabalança o peso da ciência na vida moderna. Por isso mesmo, diz ele: 
[...] o importante nas artes não é a parte científica, analisável da música, e sim aquele algo que dela emerge, mas a transcende, algo que não pode ser analisado porque não está nela, mas é dela. É uma qualidade que não pode ser adquirida pelo simples exercício de uma técnica ou um sistema: tem a ver com personalidade, dom, espírito. O que chamo bem simplesmente de - magia (BRITTEN, 2003, p. 260).

Outra vez, o "sopro do espírito" - agora por meio de um compositor famoso por, entre outras obras, um quarteto de oboé e cordas (Phantasy Quartet, op. 2). A afirmação estonteia os especialistas, os acadêmicos, cuja autoridade depende precisamente da ênfase na parte explicável e analisável que Britten olimpicamente relega a segundo plano. O trecho, parte de um discurso proferido quando o compositor recebeu o prêmio Aspen, em 1964, mostra que o tema da inspiração pode ser rejeitado em teses e dissertações, mas continua relevante para o público, assim como para os artistas.

$\mathrm{O}$ aspecto mágico de que fala Britten interessou a Wallace Stevens como "elemento irracional" na poesia, em ensaio de 1936. "O que nos interessa", diz ele, "é o processo particular da mente racional que reconhecemos como irracional no sentido de que se dá inimputavelmente" (STEVENS, 1997, p. 782). O americano toca aqui no tema da responsabilidade pela criação artística, cuja aferição se torna mais complexa em vista da impossibilidade de controle autoral sobre "a transação entre a realidade e a sensibilidade do poeta, a partir da qual surge a poesia" (STEVENS, 1997, p. 781). Fica implícito um lugar para Euterpe como Musa da poesia lírica. Diante disso, mas sublinhando a recepção estética, Stevens também relativiza a primazia da análise: "Quando achamos na poesia aquilo que nos dá uma existência momentânea num plano requintado, é necessário perguntar pelo sentido do poema?" (STEVENS, 1997, p. 786).

"Requintado"? O poeta se refere a um plano exquisite - palavra bem difícil de traduzir. Etimologicamente, trata-se de um particípio passado do verbo em latim exquirere, cujo sentido literal seria "rebuscar" (mas sem a conotação pejorativa existente em português). 
Seria o adjetivo "esquisito" na primeira acepção dada pelo Houaiss ("dificilmente ocorrente; incomum, raro, precioso, fino") - que, no entanto, não é nada usual no português brasileiro (HOUAISS; VILLAR, 2001, "esquisito, adj.”). As acepções registradas no dicionário Oxford enfatizam a excepcionalidade que o adjetivo pretende indicar, seja no uso das faculdades racionais, seja na excelência das artes: é aquilo que foi cuidadosamente procurado, o engenhoso, o seleto, bem-escolhido, o acurado ou exato, notavelmente elaborado, levado a um alto grau de perfeição ou acabamento. Mais pertinentes a essa ocorrência são em particular a quinta acepção ("De consumada excelência, beleza ou perfeição, a ponto de excitar intenso deleite ou admiração") e a terrível sexta ("Na dor, no prazer, etc.: Intenso, agudo, fundo") (SIMPSON; WEINER, 1989: “exquisite, a. and n.”).

O termo se aplica à escolha vocabular de Stevens, no trecho citado: a uma elaboração artística exquisite, corresponde uma experiência igualmente intensa de um prazer, às vezes doloroso, na esfera da fruição estética. Quando se alcança essa correlação, é que Euterpe deve andar por perto.

O influxo de Euterpe, se atentamos bem para seus frutos, elevanos acima do plano comum, sem requinte, sem escolha, para uma "existência momentânea" superior, que é quando se dá a experiência estética. Talvez a força dessa intensidade, que às vezes alcança a contemplação da tragédia, explique os olhos vidrados da Musa, em muitas representações. Por exemplo, num mosaico de Tarragona do século II d. C. (MNAT, s. d.). Euterpe olha para uma direção indefinida, que pode ser o "lugar misterioso" de um prazer "esquisito" que enlaça os indivíduos através da arte e lhes dá forma interior, a depender da atenção que cada um estiver disposto a dispensar (Figura 5). 
FIGURA 5 - Euterpe. Mosaico, opus vermiculatum sobre lajota. Catalunha, Tarragona, Villa Romana dels Munts (Altafulla), $3^{\circ}$ quartel do século II d. C. Museu

Nacional Arqueológico, Tarragona.

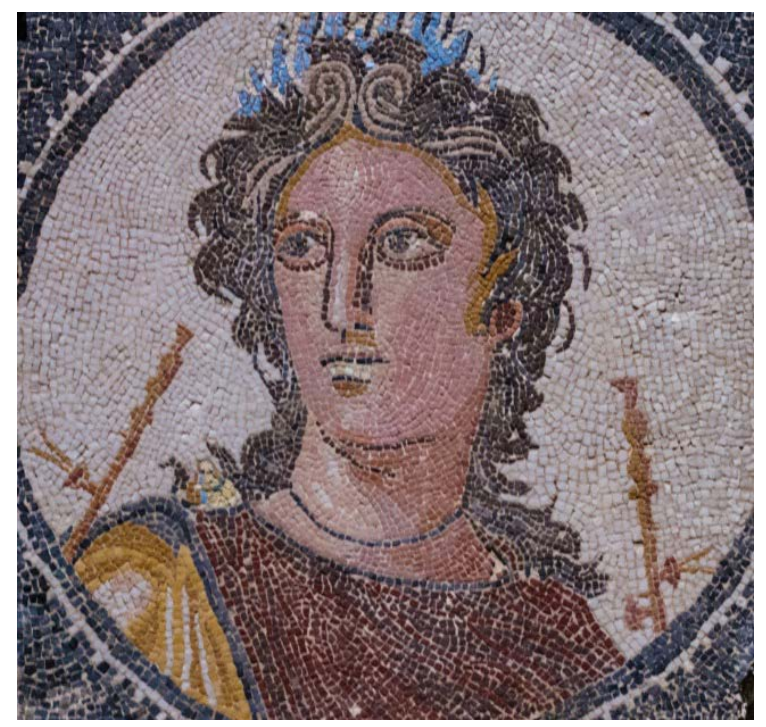

Fonte: MOSAIC..., c2019.

Também vidrado é o olhar do menino Angenor de Oliveira, aos onze, doze anos de idade (Figura 6). Mas, diferentemente da Euterpe tarraconense, o olhar dele alcança o espectador em cheio, atravessando a objetiva fotográfica e um século de distância. É o futuro Cartola, inesquecível compositor da Mangueira, no Rio de Janeiro, autor de um samba que resume os esforços da Musa - pela música e pela letra. "Cordas de aço" terá sido composta em 1968, por um artista calejado, sexagenário ou quase, de vida quase nunca fácil e reconhecimento mais do que tardio. Foi a faixa final do LP consagrador, lançado pelo selo Marcus Pereira em 1976 (OLIVEIRA, 2017). 
FIGURA 6 - O compositor e poeta mangueirense Cartola (Angenor de Oliveira) por volta dos 12 anos de idade. Rio de Janeiro, ca. 1920.

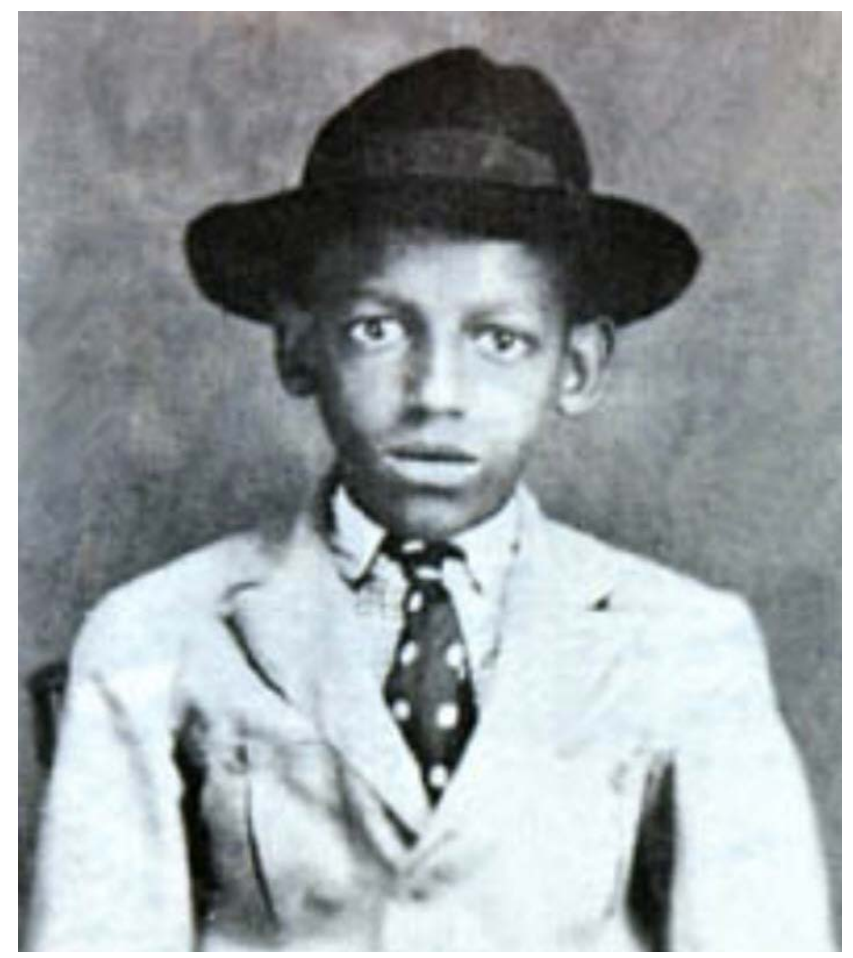

Fonte: Cartola..., c2019.

No estúdio, Cartola cantou acompanhado de músicos excepcionais. O diálogo entre o violão e a flauta ficou a cargo dos lendários Dino 7 Cordas e Altamiro Carrilho. Este faz uma curta introdução alusiva ao desfecho da melodia, cadenciada pelo conjunto percussivo e sobretudo os bordões do violonista. Com a entrada da voz encorpada, experiente do compositor, o aulete interfere em pontos dramáticos, sublinhando, comentando a letra cantada e excitando a ebriedade tão temida e perseguida, ao contraponto do incessante dedilhar do citaredo. "Ah, esse bojo perfeito", diz o poeta, referindo-se ao próprio instrumento, e através dele à sua arte, e a flauta retorna em crescendo para dar a máxima intensidade ao diálogo: "Só você, violão, compreende por que / perdi toda a alegria". O ouvinte atento então já está completamente capturado, 
e experimenta a ambivalência do prazer estético: "sofres porque queres", dirá a si mesmo.

Euterpe comparece com o prazer doce-amargo que a canção suscita, a custo da alegria perdida do poeta. A arte compreende a razão e é a interlocutora dileta, como é tão frequente na lírica, desde tempos imemoriais, para quem ele ainda confessa a esperança de uma redenção: "Aquela mulher / até hoje está nos esperando", afirma; e a pontuação da flauta começa a descender para os graves, bem quando a melodia cantada sobe para o agudo: "Na madrugada / iremos para casa cantando". A ambivalência da atividade musaica se arranja assim, nessa faixa, num xis.

É o xis do problema, diria outro sambista de renome. Inclusive porque, na repetição, a gravação termina com novo reconhecimento da perda, em melodia decrescente, acompanhada pela flauta, que desce junto.

Poucos anos após essa gravação, Cartola é homenageado, como colega, por Carlos Drummond de Andrade, em sua coluna no Jornal do Brasil. O poeta-cronista relata a situação de ouvir, de passagem, na rua, um samba do mangueirense. Alude à obra-prima "O mundo é um moinho" (do mesmo LP de 1976); reflete sobre como os mortais são moídos nessa roda, mas adverte: "Alguns, como Cartola, são trigo de qualidade especial". É o antigo lugar-comum da arte como alimento, nutrição não para o corpo, mas para o espírito. O autor de Sentimento do mundo finaliza com a explanação da paidéia almejada por Euterpe:

[...] O som calou-se, e "fui à vida", como ele gosta de dizer, isto é, à obrigação daquele dia. Mas levava uma companhia, uma amizade de espírito, o jeito de Cartola botar em lirismo a sua vida, os seus amores, o seu sentimento do mundo, esse moinho, e da poesia, essa iluminação (ANDRADE, 1980).

Cartola morreu três dias depois. Mas não sua companhia, preservada pela Musa, nas pessoas de seus admiradores. E agora mesmo, se quisermos, ele ainda está cantando, com Dino e Altamiro, que também se foram, e ainda estão tocando - no rádio, no LP, no $\mathrm{CD}$, no Youtube, no Spotify. Um botão pode acioná-los, ou um clique. Uma vez dado o 
comando, eles vivem - desde que a nossa mente se atenha e aceite a inspiração.

Essa razão existencial é o que Euterpe excita e inspira, encarnada em auletrida arcaica ou cantora pop, livre ou não da armadilha da doxa. Que os tempos atuais não lhe sejam muito favoráveis apenas acentua a sua virtude insubordinável e constante através dos tempos.

À memória do Prof. Junito de Souza Brandão

\section{Referências}

ANDRADE, C. D. de. Cartola, no moinho do mundo. Jornal do Brasil, Rio de Janeiro, 27 nov. 1980, Caderno B, p. 7.

BEEKES, R; BEEK, L. (org.). Etymological Dictionary of Greek. Leiden, Londres: Brill, 2010. 2 v.

BRANDÃO, J. de S. Mitologia grega. Petrópolis: Vozes, 1986. 3 v.

BRITTEN, B. On Receiving the First Aspen Award. In: BRITTEN, B. Britten on Music. Edição preparada por P. Kildea. Oxford: Oxford University Press, 2003. p. 255-263.

CARTOLA (compositor) - Wikipédia, a enciclopédia livre, c2019. Disponível em: https://pt.wikipedia.org/wiki/Cartola_(compositor)\#/ media/Ficheiro:Cartola-1920.JPG. Acesso em: 08 jul. 2019.

CRATERE a figure rosse di produzione italiota, particolare: Athena che suona l'aulos - 375-350 a.C. Firenze, Museo Archeologico Nazionale: La Magna Grecia in mostra. Florença, 27 mai. 2013. Disponível em: https:// museoarcheologiconazionaledifirenze.wordpress.com/2013/05/27/. Acesso em: 31 jan. 2019.

CUSUMANO, K. Madonna, Queen of Pop and Woman of the Year, is Among the Muses. Thanks to Alessandro Michele. $W$, Nova York, 11 dez. 2016. Disponível em: www.wmagazine.com/story/madonna-guccibillboard-women-in-music-awards. Acesso em: 18 dez. 2018.

FRYE, N. Anatomia da crítica. Tradução de Péricles Eugênio da Silva Ramos. São Paulo: Cultrix, 1973. 
GELMAN, J. De palabra. Poesía III (1973-1989). Madri: Visor, 1994. HESÍODO. Teogonia: a origem dos deuses. Estudo e tradução de J. Torrano. 7. ed. São Paulo: Iluminuras, 2007.

HESÍODO. Theogony and Works and Days. Tradução, introdução e notas de M. L. West. Oxford: Oxford University Press, 1988.

HOUAISS, A; VILLAR, M. (org.). Grande dicionário Houaiss da língua portuguesa. Rio de Janeiro: Instituto Antonio Houaiss e Objetiva, 2001. Disponível em: https://houaiss.uol.com.br. Acesso em: 31 jan. 2019.

LA BORDE, A. Collection des vases grecs de Mr. le Comte de Lamberg expliquée et publiée par... Paris: Didot l'Ainé, 1813. v. 1.

LEVY, G. Muse. In: GREENE, R. (org.). The Princeton Encyclopedia of Poetry and Poetics. 4. ed. Princeton NJ: Princeton University Press, 2012. p. 901-903.

MADONNA attends the Billboard Women in Music 2016 event on Dec. 9, 2016 in New York City. [Images \& Video's]. In: MADONNA Extreme, 9 Dec. 2016. Disponível em: http://madonnaextreme.blogspot. com/2016/12/madonna-womenoftheyear-december-9-2016.html. Acesso em: 31 jan. 2019.

MADONNA. Postagem no Instagram [SEM título], 9 dez. 2016. 1 Fotografia, color. Instagram: @madonna. Disponível em: https://www. instagram.com/p/BN0CWnSB8Rg/. Acesso em: 31 jan. 2019.

MALTA, P. P.; ARAGÃO, P.; LOPES, P.; PAES LEME, B. Pixinguinha e Villa-Lobos. Rádio Batuta, Instituto Moreira Salles. Rio de Janeiro, 5 mar. 2016. Programa radiofônico. Disponível em: https://radiobatuta. com.br/programa/pixinguinha-e-villa-lobos/. Acesso em: 31 jan. 2019.

MOSAIC d'Euterpe. Tarragona, (C2019. Disponível em: https://www. mnat.cat/obra/17/mosaic-deuterpe/. Acesso em: 31 jan. 2019.

MURRAY, P. The Muses and their Art. In: MURRAY, P.; WILSON, P. (org.). Music and the Muses. The Culture of Mousike in the Classical Athenian City. Oxford: Oxford University Press, 2004. p. 365-392.

OLIVEIRA, M. Cartola, 1976, Discos Marcus Pereira. Disponível em: https://sambaderaiz.org/albuns/cartola-1976/. Acesso em: 31 jan. 2019. 
OVÍDIO. Metamorphoses. Tradução de F. J. Miller. Cambridge MA: Harvard University Press, 1971.

PLATÃO. Repubblica. Edição preparada por G. Reale e R. Radice. Milão: Bompiani, 2009.

PYXIS (round box with cover) depicting a herdsman with six muses. Boston, C2019. Disponível em: https://www.mfa.org/collections/ object/pyxis-round-box-with-cover-depicting-a-herdsman-with-sixmuses-154001 . Acesso em: 31 jan. 2019.

ROSE, H. J. A Handbook of Greek Mythology. Including its Extension to Rome. Londres: Routledge, 1990.

SEMENZATO, C. À l'écoute des Muses en Grèce archaïque. La question de l'inspiration dans la poése grecque à l'aube de notre civilisation. Berlim: De Gruyter, 2017. Doi: https://doi.org/10.1515/9783110534795.

SIMPSON, J.; WEINER, E. (org.). Oxford English Dictionary. 2. ed. Oxford: Oxford University Press, 1989. Disponível em: www.oed.com. Acesso em: 31 jan. 2019.

STEVENS, W. The Irrational Element in Poetry. In: STEVENS, W. Collected Poetry \& Prose. Edição preparada por F. Kermode e J. Richardson. Washington DC: The Library of America, 1997. p. 781-792.

VASCONCELOS, A. Panorama da música popular brasileira. São Paulo: Martins, 1964. 2 v.

VERNANT, J-P. Mythe et pensée chez les Grecs. Études de psychologie historique. In: VERNANT, J.-P. Oeuvres. Paris: Seuil, 2007. v. 1, p. 239-611.

WILSON, P. The Athenian Institution of the Khoregia: The Chorus, the City and the Stage. Cambridge: Cambridge University Press, 2000.

WILSON, P. The Aulos in Athens. In: GOLDHILL, S.; OSBORNE, R. (org.). Performance Culture and Athenian Democracy. Cambridge: Cambridge University Press, 1999. p. 58-95.

Recebido em 4 de março de 2019. Aprovado em 12 de abril de 2019. 